\title{
SPECIAL EDUCATION FOR THE MILDLY RETARDED: SERVANT OR SAVANT
}

\section{SPECIAL EDUCATION FOR THE MILDLY RETARDED}

\section{Donald L. MacMillan ${ }^{1}$}

Seldom, if ever, has one single article had an impact on the field of special education comparable to that of Professor L. M. Dunn's (1968) regarding special education for minority children labelled as educable mentally retarded (EMR). The debate stimulated by that article has been extensive. Some school districts have wholeheartedly endorsed what they perceive Dunn's position to be, and have moved toward total integration of EMR-labelled children into regular classes. In addition, state departments of education have made policy decision designed to prevent misidentification of minority children as EMR. Clearly, Dunn has been an important influence in reversing a trend toward the proliferation of self-contained special classes for the EMR, which he sensed and spoke out against.

For years preceding the publication of the Dunn article, concern was expressed by many special educators as well as increasingly militant minority groups about the overrepresentation of minority children in special classes for the EMR. However, it took someone of Dunn's stature to stimulate the field into action by recommending a plan for change in an attempt to ameliorate this social problem.

I do not agree with some professionals who apparently interpret Dunn's article as "proof" that EMR classes should be totally abolished-though admittedly nowhere does Dunn himself call for such a move. Certainly, some special educators have seen EMR classes as the way to educate children with IQ's from $50-70$, and this restrictive view has proven stifling (see MacMillan, 1969). Nevertheless; total abolition of these classes seems to me premature. For these reasons it seems time for the issues regarding special class placement to be clarified and for someone to reevaluate the evidence on which the case was made by Dunn (1968).

In stating the reasons for a change, Professor Dunn presents evidence which supports his contention that special classes have proven a disservice to the mildly retarded. In the course of this paper that evidence will be re-examined, and other evidence of which Dr. Dunn was either unaware or chose to ignore will be presented. Hopefully, the discussion can bring to light the complexity of the issues presented

1. Donald L. MacMillan is Associate Profsesor of Education, University of California, Riverside, and Research Specialist, Department of Mental Hygiene, State of California. 
which must be considered in deciding the most efficacious administrative arrangement for a particular child. Finally, an attempt is made to restate the problem as I see it and make recommendations regarding it. Specifically, the issues raised, and the bases on which my case is built, are:

1) Though self-contained classes fail to promote academic and personal growth of the dimensions originally expected, such classes are still useful for some low-IQ children.

2) The method of identifying children as mentally retarded described by Dunn (1968), reflects a strict psychometric definition of mental retardation and thereby ignores the consensus AAMD definition.

3) Evidence on the effects of placement and labelling is sorely lacking; hence these effects must not be considered as a sole cause of achievement and adjustment problems.

4) Adjustments in the environment which are strictly cognitive in nature are unlikely to aid learning in low-IQ children whose problems are emotional or motivational-a description which probably fits many minority children of low IQ.

FOCUS ON EXCEPTIONAL CHILDREN is published monthly except June, July, and August as a service to those concerned with mentally retarded and emotionally disturbed children. Subscriptions rates, $\$ 9.50$ per year. Copyright 1971 Love Publishing Company. All rights reserved. Reproduction in whole or part without written permission is prohibited. Printed in the United States of America. Second class postage is paid at Denver, Colorado.

Executive and Editorial Offices 6635 East Villanova Place Denver, Colorado 80222

Telephone (303) 757-2579

EDITORIAL BOARD

Edward L. Meyen

University of Missouri

Richard J. Whelan

University of Kansas Medical Center

Frances Missing

Senior Editor
Stanley F. Love Publisher
5) The real issue is not whether special classes or regular classes are better for the mildly retarded, but rather the extent to which a wider range of individual differences can be accomodated in the regular class.

One point must be clarified before moving on. In no way am I arguing that homogeneous classes for children of IQ's ranging between $50-70$ or 75 is the best arrangement. Rather, on the basis of the evidence uncovered so far, I would contend that a self-contained special class may well be the best placement for certain low-IQ children.

\section{SELF-CONTAINED SPECIAL CLASSES}

A given administrative arrangement is neither good nor bad. As Goldberg et al. (1961) pointed out with regard to the gifted, what really counts is what is done with the group once it is established. The argument applies equally well when applied to the lower end of the intellectual distribution; hence, poor implementation should not be interpreted to invalidate the administrative organization. Indeed, a debate over which administrative arrangement, special class or regular class, for lowIQ children categorically degenerates into an academic exercise with no meaning for the real world.

For any given case, the better placement depends on many variables unspecified in the question of the efficacy of special or regular classes for low IQ children. Among the questions which must be raised are the following: (a) How competent are the teachers in each setting for dealing with the specific characteristics of the child in question? (b) To what extent has the child developed prerequisite readiness skills in the regular class? (c) How does the child respond to the consequences likely to be used in the regular class? (d) What is the general level of functioning of other children in the regular class, or to what degree will that child deviate from the other children? (e) Does the regular class teacher have the time needed to accomodate this child? Therefore, what is needed is an interaction model which includes, at least:

administrative arrangement $x$ child $x$ teacher $x$ children in alternate placements, perhaps the least important of which is the administrative arrangement. 


\section{EFFICACY STUDIES}

As Dunn suggests (1968, p. 8), an examination of studies on the efficacy of special classes is in order. Such an examination should, however, begin with the methodology utilized, not with the results. With few exceptions (e.g., Goldstein, Moss, and Jordan, 1965) these studies could be described as poorly designed, replete with sampling biases which render the results uninterpretable. For example, in both the Cassidy and Stanton (1959) and Thurstone (1960) studies, the investigators failed to randomly assign subjects to the self-contained and regular class placements. Therefore, the finding that EMR children in the regular classes exceeded the EMR children in the self-contained classes on some achievement measures is difficult, if not impossible, to interpret. More specifically, were those EMR children who were allowed to remain in the regular class left there because they were, in fact, academically advanced by comparison?

At the same time, the means of assessing "adjustment" in these two studies are questionable. Cassidy \& Stanton (1959) used teacher ratings as one measure, while the Thurstone (1960) study used a sociometric device. In the former case, the validity of the teachers' ratings is questionable due to variable frames of reference while the latter procedure makes the results difficult to compare, since acceptance within a special class is hardly comparable to acceptance in a class with higher ability children.

In the one study where EMR subjects were randomly assigned to the treatments (Goldstein, Moss, and Jordan, 1965), EMR's in the regular class were found to achieve significantly better in reading at the end of a two-year period. However, by the end of four years the EMR children in the self-contained classes had caught up to the former group. Post hoc comparisons of low-IQ children within each group revealed that this subsample achieved significantly better on certain achievement measures than did the low-IQ subsample placed in regular classes.

Hence, the best controlled of the studies concerned with efficacy of special classes does little to undermine Dunn's contention that special classes have failed to live up to original expectancies. Raised as an empirical question, the fact that such classes have not been found to result in superior achievement or adjustment must not be interpreted to mean that there are no differences in the two placements. In the cases where significantly superior performance was found for the regular class placement (Cassidy \& Stanton, 1959; Thurstone, 1960), the sampling bias renders the results questionable.

Using different criteria (i.e., social competence and economic efficiency) than typical achievement and adjustment measures, Porter and Milazzo (1958) concluded that the post-school adjustment of children who had been enrolled in special classes was markedly superior to that of equally retarded children who had remained in regular classes. Again, the small sample size (twelve in each group) and the sampling procedures render definite conclusions hazardous.

While Dunn (1968) cites Kirk's (1964) review as supportive of his contention that retarded pupils make as much or more progress in regular grades as they do in special education, he fails to include Kirk's mention of the pitfalls inherent in the studies which deal with the special-versus-regular class debate:

1) Problems in sampling-taking in situ groups to compare.

2) No control over the length of time spent in special classes prior to the evaluation.

3) Lack of a delineation of a special class, the curriculum, or the teacher qualifications.

4) Measurement instruments used in the studies were often improvised, and therefore of questionable validity and reliability.

Kirk goes on to conclude that "until we obtain well-controlled studies of a longitudinal nature, our opinions about the benefits or detriments of special classes will remain partly in the realm of conjecture." (Kirk, 1964, p. 63)

The teacher variable has defied educational researchers in evaluating curricula and administrative arrangements since the beginning of educational research. Likewise, the failure to control this variable has plagued the attempts at evaluating special classes. Any particular low-IQ child placed with the "right" teacher, regardless of the administrative arrangement, is likely to benefit. Unfortunately the reverse is just as true. In a recent article, Davis (1970) argues that because of the demand for more and more teachers in classes for the mentally retarded, requirements for specific credentials are frequently modified or postponed. While one would not consider being operated on by a surgeon operating on a "postponement of requirements" or being defended in a court of law by a lawyer operating on a "partial fulfill- 
ment of requirements," we seem satisfied to allow children identified as needing special teaching skills to learn under the direction of a teacher whose preparation fails to meet minimal standards as set by a particular state. Is it any wonder, then, that the children assigned to such a setting have not progressed at a rate considered appropriate? To what extent are the "failures" of special classes attributable to the administrative arrangement per se, and to what extent attributable to the teacher's inadequacies?

Related to the above discussion is the possibility that teachers of the mentally retarded enjoy little status in the schools. A study by Jones and Gottfried (1966) had teachers rate the prestige of teachers of various exceptionalities (e.g., severely retarded, blind, gifted, orthopedically handicapped). They found that teachers of the EMR enjoy little status among colleagues and individuals in teacher-training. The most dramatic finding, however, was that the teachers of the EMR rated themselves lower than they were rated by regular classroom teachers. Hence, not only are they assigned little prestige in the schools, but they appear to accept the lack of prestige as being justified. If the above findings are taken at face value they well might support Dunn; however, it may also reflect a phenomenon related to the type of teacher attracted to this phase of special education. If we attract those threatened by regular classes, or those who are not as capable, then the failure of special classes must not be interpreted as a failure of the administrative arrangement per se, but rather a failure of implementation. If we cannot determine how to individualize in a setting where there is one teacher for 1518 students, are we ready to advise on how individualization can occur in a setting with thirty children and one teacher?

\section{IDENTIFICATION PROCESS}

On the point that numerous minority children are inappropriately labelled as EMR, I find myself in complete agreement with Professor Dunn. The stigma attached to this label very probably operates in direct opposition to the potential advantages attributed to reduced pupil/teacher ratio. Of course, special educators tend not to participate in the identification procedure, often deferring judgment instead to the psychologist, psychometrist, or physician-and in most cases it is the latter upon whom the focus of this criticism should prob- ably be directed.

The precise reason so much consideration went into the development of a flexible definition of mental retardation by the American Association on Mental Deficiency with the support of the National Institute of Mental Health was to deal with the borderline cases (Heber, 1959; revised, 1961). Severely and profoundly retarded individuals are identified with a minimum of difficulty, but borderline cases require careful attention. The definition agreed upon was, "Mental retardation refers to subaverage general intellectual functioning which originates during the developmental period and is associated with impairment in adaptive behavior." (Heber, 1961, p. 3).

Clearly, three specific criteria must be met before an individual is to be considered retarded: (1) IQ at least one standard deviation below the population mean, (2) mental retardation must occur prior to age 16 , and (3) there must be evidence indicating impaired adjustment. The absence of any one of the three criteria should preclude placement in a special class. In practice, an intelligence test may on occasion be used to "justify the label 'mentally retarded" (Dunn, 1968, p. 9); however, such a practice goes on in violation of criteria constituted to determine the presence of the condition or state labelled as mentally retarded.

Most professionals in the field of mental retardation feel somewhat uneasy about the reliance upon IQ in diagnosing retardation, particularly when dealing with borderline cases involving minority children from culturally different backgrounds. Clausen (1967) stated what many others have come to realize when attempting to use the AAMD classification system: namely, that there are few guidelines for determining an impairment in adaptive behavior. As a result, one makes extremely subjective evaluations of "social adequacy"; hence, clinicians ignore social adequacy and make the diagnosis on the basis of general intellectual functioning alone.

Alternative tacks may be taken in attempts to deal with the above problem. Clausen (1967) suggests the cut-off be dropped from one standard deviation below the mean (i.e., IQ $=84-85$ ) to two standard deviations (i.e., $\mathrm{IQ}=68-70$ ) for evidence of subaverage intellectual functioning. He contends that below IQ $=70$ or 75 individuals tend to show evidence of impaired social adaptive behavior caused by the low level of intellectual functioning (Clausen, 1967, p. 743). This would appear to be Dunn's preference. In his recent address, 
Dunn (1970) set the following IQ cut-offs for EMR placement: Anglo children, IQ $=70$; American Indian children, $\mathrm{IQ}=65$; and inner-city black children, $\mathrm{IQ}=55$. Such limits are arbitrary and still reflect a psychometric definition of retardation of which Dunn (1968) was critical.

Another approach would be to develop more objective means of assessing adaptive behavior which would be valid for use with borderline children of minority status. Such an attempt has been made by Mercer (1970) on an experimental basis. Her adaptive behavior scales and pluralistic norms provide an interesting and promising alternative to the strict psychometric classification system used by some.

It has been my experience that committees charged with considering EMR placement for a child approach the task with far more consideration than was implied by Dunn. Before such a conference is called, two pieces of information are already available. First, the child's performance in the regular class has been poor enough, by comparison to the class as a whole, to attract the teacher's attention. Second, an individual intelligence test (usually supplemented by an entire battery of tests) has been administered on which the child scores below the district cut-off for EMR (usually IQ of 70).

At this point, I must agree that minority children are at a particular disadvantage when it comes to taking an intelligence test. Specifically, I suspect emotional and motivational variables prevent many such children from performing near the level of which they are capable. Riessman (1962) refers to this as the issue of the relation of examiner to examined. When examiners who differ from the children on the basis of social class and ethnic origin see the child briefly, it is difficult to establish the type of rapport conducive to best functioning of the child (Pasamanick \& Knobloch, 1955). Performance, then, becomes difficult to evaluate since it could reflect the effects of poor relations between the examiner and the examined or a true measure of a child's abilities and achievements. Psychologists and psychometrists charged with evaluating children from different social and/or ethnic backgrounds might find the procedures reported in Hertzig et al. (1968) or the "optimizing" test conditions used by Zigler and Butterfield (1968) as helpful in countering this source of bias.

One may argue that tests of intelligence in use are culturally biased and thereby discriminate against the minority child. However, they are biased in the same direction as are the schools. As a result, these instruments do have rather good predictive validity on a short term basis. Taken in combination (regular class problems plus low IQ), these bits of evidence tell us that this child is likely to continue encountering problems if he is left in the regular classroom and presented with a standard curriculum. In other words, this child needs something "special." In such a context, special education is not synonymous with self-contained class.

Among minority children meeting the two criteria specified above, there are at least several types of children.

1) Bilingual children (e.g., Chicano, Puerto Rican) in need of accommodation in the area of language, but who, genotypically speaking, are not defective or retarded.

2) Children from environments described as impoverished, in that they are lacking in materials or experiences considered beneficial to a child in adjusting to the school. Again, these children are not genotypically retarded.

3) Children who have developed failure sets-i.e., who have poor self-concepts and expect to fail before they even attempt a task.

4) Children of dull-normal ability with so much emotional overlay that their performance in school and on the intelligence test is depressed below the district cut-off.

5) Children who simply received a poor genetic pool or suffered prenatal, paranatal, or postnatal damage resulting in lowered cognitive capacity. These children are genotypically retarded.

Obviously, one could go on to specify greater numbers of types and any typology suffers from ignoring within-type variance. However, the point to be made concerns the nature of the "something special" needed by each of the types of minority children of low IQ described. In what kind of administrative arrangement can an individual child maximally benefit? In some cases (such as those described in 2 and 3 above) 
a resource specialist, as described by Dunn, may be sufficient. In others (such as 1, 4, and 5) a more intensive program may be needed. Some, in fact, may be best off in a self-contained special class! In none of the cases should the child be allowed to flounder in a regular class with no ancillary services.

Before leaving the topic of placement, I should mention the fact that many minority children whose IQ's alone would warrant EMR placement remain in regular classes. In her demographic study, Mercer (1970) identified a group of children she labelled as eligibles-IQ below 75 but for a variety of reasons not placed in EMR classes. Most of these eligibles were functioning adequately in the regular program. It should be noted, however, that IQ alone did not appear to automatically result in EMR placement. Rather, other variables in addition to IQ were considered, and those with low IQ but adequate functioning remained in regular classes.

\section{EFFECTS OF PLACEMENT}

While my suspicion coincides with Dunn's with respect to the operation of a self-fulfilling prophecy, the dynamics underlying such a phenomenon are complex and far from fully understood. If one could extrapolate so easily from the Rosenthal and Jacobsen (1968) work as is implied by Dunn, the problem could be solved im. mediately by simply labelling the children under consideration "gifted" and thereby increase the teachers' expectancy for them to succeed. Secondly, the methodology underlying research on expectancy appears to affect the results considerably (see Barber \& Silver, 1968a, 1968b, and Rosenthal's response, 1968), and the hypothesis testing utilized is often inappropriate. Thirdly, using the Rosenthal \& Jacobsen (1968) work to any extent as support for the operation of a self-fulfilling prophecy is hazardous in light of the telling critique of Thorndike (1968). In discussing the study he states:

Alas, it is so defective technically that one can only regret that it ever got beyond the eyes of the original investigators! Though the volume may be an effective addition to educational propagandizing, it does nothing to raise the standards of educational research. (1968, p. 708)

In addition to the self-fulfilling prophecy, the principal objection raised by Dunn concerns the effects of labels upon the child. Granted, the label "mentally retarded" is not a badge of distinction. Neither, however, is being called "dummy" by higher ability children in the regular class typically prescribed for such children. Again, the effects of such a label are likely to be varied. In discussing the concern over the negative effects of such labels, Goldstein (1963) writes:

There are those who wish to avoid the false positives inherent in early placement. They express the very reasonable fear that some children will be tainted unjustifiably with the label "retarded" if they are admitted to a special class at age six and later gain intellectually beyond the upper limits for such classes: However, we must not overlook the fact that such a child, through his adequate achievement in an appropriate regular class placement, stands an excellent chance of erasing the label.

Instead of becoming preoccupied solely with labels and stigma, we might do well to look at the other side of the coin and ask what effects delayed placement has on the personality development of the child, the status he acquires among his regular class peers, and the pressures placed on the family. In all justice, we cannot close our eyes to the fact that the retarded child in the regular class can be and frequently is labelled by his peers in much the same way as children in special classes. (1963, pp. 12, 52)

Some empirical evidence is available on the last point made by Goldstein. Johnson (1950) and Johnson and Kirk (1950) studied the social position of retarded children in regular classes. Unfortunately, the sampling problems discussed earlier regarding efficacy studies contaminates the findings of these studies as well. A type of psychological segregation was found typical for retardates in regular class placements in both studies. Johnson (1950) did, however, find approximately $5 \%$ of the retardates identified as "stars" on a sociometric device. It would be interesting to have descriptions of these children, in that it might indicate characteristics associated with high social standing in a regular class which could aid us in determining which EMR children might profit from such placements.

The evidence cited by Dunn as supportive of the negative impact of such labels warrants a closer look. Goffman (1961) does, in fact, discuss the stripping and mortification of the self-important concepts indeed in understanding the careers of inmates of institutions such as monasteries, military camps, prisons, and mental hospitals. Note, however, that the institutions mentioned do not even include institutions for the mentally retarded. Among the degrading experiences described (Goffman, 1957) are the removal of personal clothing and possessions, the restrictions on privacy, the reduction of independence of movement and decision, the restriction of communication with the outside world. These experiences are hardly typical in a special class for the EMR. 
Hence, extrapolation of findings from these settings to a setting (i.e., self-contained EMR class) which is not an institution and contains individuals who are labelled in an altogether different manner from the above groups seems risky at best. At the same time, Dunn failed to mention the work of Edgerton \& Sabagh (1962) which did apply Goffman's constructs to patients in an institution for the mentally retarded. These investigators studied stripping and mortification as they applied to the careers of the mentally retarded and their findings were not consistent with those of Goffman (1961).

Edgerton \& Sabagh (1962) suggest that the mortifications of the self may be fewer within institutions for the high-grade retardate than in the case of the outside. In fact, for the high-grade retardate there may be certain aggrandizements of the self accrued as a result of having low-grade retardates with whom to compare himself for greater social success within the institution, the support and approval from ward personnel, and the opportunity for validation of his normality provided by his peers. As noted by Cromwell (1963), these arguments are reminiscent of the rationale presented by Johnson \& Kirk (1950) with regard to the EMR in special classes. That is, the social position of the EMR is improved when placed in a setting where the mean IQ is reduced.

The effect a label such as "mentally retarded" has on a given child depends on a whole host of variables. To begin with, it is necessary to examine his pre-identification career. To what extent has the child been labelled "dumb" or "stupid" by peers or others (e.g., parents, teachers, and other adults)? To what extent has he been isolated or rejected socially in the regular class and in other social situations? Answers to these questions provide clues to the extent to which the self has suffered mortification before he has been formally labelled and placed.

Secondly, one must assess whether or not the child accepts or rejects these external evaluations. If he rejects them, he is also likely to reject the "mentally retarded" label when the educators try to attach that to him. Edgerton \& Sabagh (1962) describe children coming from minority families of low socioeconomic status as follows:

This nonacceptance may have been facilitated by several circumstances. For instance, the entire family of the retarded person may have been rejected and mortified by the community at large and feel the need to protect its members against the onslaught of "authorities." Many of the mentally retarded come from families of low ethnic or socio- economic status, and the family members may have had humiliating experiences with law enforcement or welfare agencies. Such a family will protect its members against those who "accuse" them of mental retardation, and may not even believe that the accused actually is retarded, since his intellectual level may not be much below that of his relatives. To them, this may simply be another instance of discrimination against the whole family. (1962, pp. 265266)

In such an instance, that child may be immunized against mortifications of the self, in which case the label may have far less effect than would be the case where the child accepts the label as accurate.

Once a child is identified, labelled, and placed in a special class, it would again be helpful to understand whether he accepts the label as accurate or whether he denies the accuracy of such a label. Should a child reject the label and find himself in a class with children of clearly inferior status, he is able to derive certain aggrandizements by means of comparison. Hence, he renews his attempt to define the self as adequate and rejects those things that challenge such a positive selfperception. It may be that for one type of low-IQ child the special class provides a haven which supports his denial of retardation, whereas a regular class would confront him with evidence and confirmation of his retardation in that his peers would be clearly superior academically. Such a situation would confirm the accuracy of such derogatory labels and disarm the child of his defense mechanisms.

Meyerowitz (1962, 1967) did study the effects of placement on personality characteristics of the mentally retarded, and it was done within the context of a study in which the subjects were randomly assigned to classes (i.e., Goldstein, Moss, \& Jordan, 1965). He did find more self-derogation in children placed in special classes; however, the findings are based on an instrument (Illinois Index of Self-Derogation) of unknown validity and reliability.

In conclusion, we do not yet understand the effects of placement on personality. On the one hand we find evidence (Meyerowitz, 1962) indicating that the child suffers in a special class, while on the other the evidence indicates that he suffers in a regular class (Johnson, 1950; Johnson \& Kark, 1950). In other words according to the evidence the child can't win-but all of the evidence is of questionable validity in terms of sampling bias, lack of control of pre-placement experiences, and the questionable nature of the criterion instruments. 


\section{COGNITIVE ADJUSTMENTS}

Any discussion of grouping, of which special classes are one form, must ultimately consider the flexibility, or inflexibility, of a particular grouping arrangement. Special classes for low-IQ children came to be considered the best way to educate such children. Paradoxically, a field committed to individual differences appears to have assumed a homogeneity within the group labelled "mentally retarded." Despite the failure of evidence to conclusively support the special class arrangement, children achieving IQ's in the EMR range have been placed in such classes and taught "the EMR curriculum," since it was assumed that they share common characteristics. About the only characteristic on which there is any commonality is on IQ (see Berkson, 1966), while on virtually every other characteristic there is as great, if not greater, intragroup variability as among nonretarded children. Yet the adaptations which occurred have been principally cognitive adaptations of the environment.

In an earlier article, MacMillan (in press) argued that attempts to adapt the environment in special classes for low-IQ children have been basically cognitive adaptations. It is as if the line of reasoning went as follows: Since these children are mentally retarded, remediation must be designed that will ameliorate their mental deficits. Yet the literature abounds with evidence which indicates that for a high proportion of low socioeconomic status, low-IQ, children, the problems in learning (or more accurately performance) originate in the motivational sphere rather than in the cognitive sphere (see Zigler \& Butterfield, 1968; MacMillan, in press). Hence, one of the reasons special classes have failed to achieve the degree of success hoped for may lie in the fact that these environments have tried to treat problems originating in the motivational sphere by adapting the environment to treat cognitive deficits. Such a lack of balanced emphasis would seem to doom a program to failure.

Zigler (1966) has summarized extensive evidence which indicates that motivational and emotional variables depress the performance of retardates below the level indicated on the basis of their cognitive development. In his American Educational Research Association address (1968), many of the findings with institutionalized patients were generalized to disadvantaged children. While space does not permit a comprehensive review of motivationally-related variables which probably affect academic performance (see MacMillan, in press), three variables have been selected in order to show how such phenomena depress performance levels of disadvantaged children below what would be expected. The three variables are: expectancy for failure, positive and negative reaction tendencies, and outerdirectedness.

Expectancy of failure. As a result of personal academic failure and social "histories of failure," many children develop problem-solving approaches characterized by the primary motivation to avoid failure rather than to achieve success. Failure occurs so often in their life space that such children approach a new task with an expectancy to fail before they even attempt the task (MacMillan \& Keogh, in press). The development of a failure set often results in a lowered level of aspiration, which prevents a child from attempting tasks slightly beyond his present level of achievement.

Clearly, teachers must reverse this failure set if the child is to progress at the rate of which he is capable. Teachers cannot allow the child to avoid tasks which are slightly beyond him; yet, at the same time, they must protect the child from experiencing unnecessary additional failure. Techniques such as prompting, as opposed to confirmation, may provide a means to guarantee success while still "challenging" him with tasks which are not trivial and for which successful completion represents mastery.

Positive and Negative Reaction Tendencies. Zigler (1966) labelled the desire to interact with an approving adult as the "positive reaction tendency," and the wariness of adults as the "negative reaction tendency." Children who have experienced social deprivation desire to interact with an approving adult and at the same time are hesitant to do so because of their many negative encounters with adults (i.e., teachers). These two phenomena are thought to be positively related to the amount of social deprivation experienced and the amount of negative interaction with adults. In describing the operation of these two variables with disadvantaged children, Zigler writes:

Children who do not receive enough affection and attention from the important adults in their life space, suffer in later years from an atypically high need for attention and affection. We find that such children, when faced with cognitive tasks, are not particularly motivated to solve the intellectual problems confronting them. Rather, those children employ their interactions with adults to satisfy their hunger for attention, affection, and yes, as unscientific as it may be, their need for love. (Zigler, 1968, p. 21) 
As the child expends energy protecting the self, less energy is available for solving cognitive or academic tasks. Hence, the teacher must cope with these motivational variables before the child can devote his energies toward the solution of academic tasks.

Related to the above discussion is the child's reinforcer hierarchy: a construct unique for each individual. Zigler (1968) contends that being correct is not as high on the hierarchy for disadvantaged and retarded children as it is on the hierarchy of a middle-class, nonretarded child. Therefore, one cannot assume that lower-class EMR's are putting forth a maximum effort in order to be correct. In fact, there is evidence to the effect that such children perform significantly better under extrinsic reward conditions than under intrinsic reward conditions (Keogh \& MacMillan, in press; Terrell, Durkin, \& Wiesley, 1959). Hence, it is essential that incentives be found on an individual basis which serve as reinforcers and which do result in maximum effort on the part of the child.

Outerdirectedness. Repeated failure can also result in a problem-solving style characterized as outerdirected. Zigler described it as follows: “. . the retarded child comes to distrust his own solutions to problems and therefore seeks guides to action in the immediate environment." (1966, p. 99). As a result the child comes to over-rely on external cues, a tendency which runs counter to a normal developmental trend in which children become more inner-directed as cognitive development releases the child from his dependence on external cues.

MacMillan (in press) describes and suggests techniques for dealing with children exhibiting these motivational characteristics. As Dunn (1968) describes the role of the resource teacher, the adaptations of the environment are still primarily cognitive in nature. As such, the resource teacher arrangement for serving those low-IQ children whose performance deficits originate in the motivational sphere would seem as inappropriate as have those self-contained classes wherein the environmental adaptation has been cognitive in nature. Regardless of the administrative arrangement into which these children are placed, such children, in substantial numbers, are likely to manifest a high expectancy for failure, positive and negative reaction tendencies, and outerdirectedness. Unless these motivational variables are dealt with by teachers, children of this type are unlikely to succeed in an integrated situation to any greater extent than they have in the special class.

\section{RESTATEMENT OF THE PROBLEM}

Special educators must not allow the present issue to become one of special classes versus regular class placement lest they find themselves in a quagmire analagous to that which resulted from the nature-nurture debates over intelligence. Yet, that is precisely what seems to be developing: polarization in which one group condemns special classes while others feel compelled to defend them. Implicit in the title of Dunn's (1968) article is the notion that special education and self-contained classes are synonymous, a notion which must be rejected.

The larger issue, and one which if debated and researched could prove fruitful is: To what extent, and under what circumstances, can a wider range of individual differences be accommodated in the regular class than is presently the case?

Attempts to answer this question would, first of all, have to determine the extent to which regular class teachers are accommodating the range of individual differences represented in their classes at present. Despite the new developments cited by Dunn, the evidence indicates that regular class teachers are unable to cope with the range of abilities they are presently faced with; hence the introduction of children who deviate more markedly would seem inadvisable. While the list of characteristics (i.e., individual differences) related to success in school is long (e.g., achievement, behavior, language abilities, motivational characteristics), the IQ will be used for illustrative purposes, because it is the one common variable on which EMR children differ from most children in the regular classes.

Figure 1.

\begin{tabular}{lllll}
\hline TMR Class EMR Class & Regular Class & Gifted Class \\
\hline $\mathrm{IQ}=25$ & $\mathrm{IQ}=50$ & $\mathrm{IQ}=75$ & $\mathrm{IQ}=100$ & $\mathrm{IQ}=125 \quad \mathrm{IQ}=150$
\end{tabular}

At present, a regular class typically contains children with IQ's between 75 and 125. Those children whose IQ's fall below 75 or above 125 or 130 are thought to require "special" adaptations in order that they can maximally benefit from the educational experience. After all, that's virtually the definition of the exceptional child. Now the question becomes, how can we modify the regular class in such a way as to enable the child with 
an IQ below 75 to benefit maximally from that setting? Hopefully, in attempts to modify the regular class in order to accommodate those children with an IQ below 75, a variety of educational models will be developed, implemented, and evaluated. Dunn (1968) outlines one such model in his article, i.e., the resource teacher to supplement the regular teacher. This model must not, however, come to be accepted as the best way to educate low-IQ children any more than the self-contained class has in the past been thought to be the best way. There should not be a proliferation of resource teachers, but rather a proliferation of different models all designed to provide for the accommodation of a wider range of individual differences in the regular class.

No one to date has advocated the integration of TMR children into regular classes. Obviously, they deviate too markedly on too many variables to make that arrangement feasible. So, however, do many EMR children; among their number will be some borderline cases of minority status. In the immediate future, the removal of large numbers of EMR's from special classes and replacement into regular classes would seem inadvisable in that the regular classes do not appear capable of handling them. For the time being, then, it seems desirable to focus our energies and resources on three fronts:

1. Preventive Programs. Rather than constantly focusing our resources on the remediation of problems once they exist, we might focus on the prediction and prevention of learning problems. For instance, one might look to the possibility that certain learning problems occur because of unfortunate environmental demands which the student cannot meet. One might be able to identify certain skills (e.g., high verbal ability, docile classroom behavior) which are essential if a child is to be successful in a given teacher's class. If a child does not possess these skills, he becomes a likely candidate for failure in that teacher's class. Hence, it may be possible to prevent failure (and subsequent EMR referral) for some children by matching their abilities with a teacher in whose class these abilities enhance the possibility for success.

2. Transitional Programs. Assuming that the misidentified children in special classes for the EMR can be identified, the next concern is how does one enable them to move back into the regular program.
Clearly, if such children are thrust back unaided the likelihood for success is minimal. Even though such children may warrant reassignment on the basis of IQ and social adjustment, most curricula for EMR classes lag behind in the presentation of tool subjects. Therefore, intensive acceleration in tool subjects is essential if these children are to be placed in regular classes with their peers. How can transition be facilitated? A variety of transitional programs should be designed, implemented, and evaluated in attempts to answer the above question.

3. Model Regular Programs. At present, regular class teachers are unable to cope with the range of individual differences they find in their classes. Therefore, without rather radical modifications in the classroom organization and the development of teacher competencies not presently possessed, the feasibility of inserting children who deviate more markedly is questionable. The resource specialist described by Dunn (1968) may provide one model. Competency-based models, in which skills teachers must possess are specified, must be developed and evaluated. Subsequently, regular class teachers are going to have to be retrained or replaced. The former alternative will require inservice training of teachers, and this will require follow-up procedures to insure that the competencies taught are being developed and employed.

The innovations mentioned above will require development of many educational models, implementation of these models, and their evaluation. This means cooperation between researchers and school personnel. Without such cooperation, the results of such studies are likely to be invalidated by the lack of controls described earlier with regard to the special versus regular class studies. Unless the quality of the research is high, it will not provide us with the necessary information on which we must make educational decisions regarding children. School personnel will have to endure some inconveniences in order that variables known to affect dependent measures can be controlled (e.g., sampling, teacher variable). Conversely, researchers must involve school personnel from the earliest stages so that they can provide input on concerns of teachers and constraints operating in the school setting. By working in concert re- 
searchers might control independent variables sufficiently to achieve tight research, and at the same time research questions that will be seen as important by public school personnel.

\section{REFERENCES}

Barber, T. X., \& Silver, M. J. "Facts, Fiction, and the Experimenter Bias Effect." Psychological Bulletin Monograph, 1968, 70, 1-29 (No. 6, pt. 2).

Barber, T. X., \& Silver, M. J. "Pitfalls in Data Analysis and Interpretation: A Reply to Rosenthal." Psychological Bulletin Monograph, 1968, 70, 48-62.

Berkson, G. "When Exceptions Obscure the Rule." Mental Retardation, 1966, 24-27.

Cassidy, V., \& Stanton, J. "An Investigation of Factors in the Educational Placement of Mentally Retarded Children: A Study of Differences Between Children in Special and Regular Classes in Ohio." U.S. Office of Education Cooperative Research Programs, Project No. 043, Columbus: Ohio State University, 1959.

Clausen, J. "Mental Deficiency: Development of a Concept." American Journal of Mental Deficiency, 1967, 71, 727-745.

Cromwell, R. L. "A Social Learning Approach to Mental Retardation." In N. R. Ellis (Ed.) Handbook of Mental Deficiency. New York: McGraw-Hill, 1963, pp. 41-91.

Davis, F. R. "Demand-Degradable Teacher Standards: Expediency and Professional Thantos." Mental Retardation, 1970, 8, $37-40$.

Dunn, L. M. "Special Education for the Mildly Retarded-Is Much of it Justifiable?" Exceptional Children, 1968, 35, 5-22.

Dunn, L. M. “The 70's: A Decade of Restitution from Special Miseducation for the Retarded." AAMD Region II Annual Fall Conference, Los Angeles, California, Nov. 14, 1970.

Edgerton, R. B., \& Sabagh, G. "From Mortification to Aggrandizement: Changing Self-Conceptions in the Careers of the Mentally Retarded." Psychiatry, 1962, 25, 263-272.

Goffman, E. "Characteristics of Total Institutions." Symposium on Preventative and Social Psychiatry. Washington, D.C.: U.S. Government Printing Office, 1957.

Goffman, E. Asylums: Essays on the Social Situation of Mental Patients and Other Inmates. Garden City, N.Y.: Anchor, 1961.

Goldberg, M., Justman, J., Parson, A. H., \& Hage, J. "The Effects of Ability Grouping: A Comparative Study of Broad, Medium, and Narrow-Range Classes in the Elementary School." Horace-Mann-Lincoln Inst. Interim Report. New York: Teachers College, Columbia University, 1961.

Goldstein, H. "Issues in the Education of the Educable Mentally Retarded." Mental Retardation, 1963, 1, 10-12 52-53.

Goldstein, H., Moss, J. W., and Jordan, L. J. "The Efficacy of Special Class Training on the Development of Mentally Retarded Children." U.S. Department of Health, Education and Welfare, Office of Education, Cooperative Research Project No. 619, Urbana: Institute for Research on Exceptional Children, University of Illinois, 1965.

Heber, R. F. "A Manual on Terminology and Classification in Mental Retardation." American Journal of Mental Deficiency, Monograph Supplement (Rev. ed. 1961), 64, 1959.

Hertzig, M. E., Birch, H. G., Thomas, A., and Mendez, O. A. "Class and Ethnic Differences in the Responsiveness of Preschool Children to Cognitive Demands." Monographs of the Society for Research in Child Development, 1968, 33, No. 1, Serial No. 117.

Johnson, G. O. "A Study of the Social Position of Mentally
Handicapped Children in Regular Grades." American Journal of Mental Deficiency, 1950, 55, 60-89.

Johnson, G. O. and Kirk, S. A. "Are Mentally Handicapped Children Segregated in the Regular Grades?" Journal of Exceptional Children, 1950, 17, 65-68.

Jones, R. L., and Gottfried, N. W. "The Prestige of Special Education Teaching." Exceptional Children. 1966, 32, 465468.

Keogh, B. K., and MacMillan, D. L. "Effects of Motivational and Presentation Conditions on Digit Recall of Children of Differing Socioeconomic, Racial, and Intelligence Groups. American Educational Research Journal, in press.

Kirk, S. A. "Research in Education." In H. A. Stevens and R. Heber (Eds.), Mental Retardation: A Review of Research. Chicago: The University of Chicago Press, 1964, pp. 57-99.

MacMillan, D. L. "An Examination of Developmental Assumptions Underlying Special Classes for Educable Retardates." California Jourmal for Instructional Improvement, 1969, 12, 165-173.

MacMillan, D. L. "The Problem of Motivation in the Education of the Mentally Retarded." Exceptional Children, in press.

MacMillan, D. L., and Keogh, B. K. "Normal and Retarded Children's Expectancy for Failure." Developmental Psychology, in press.

Mercer, J. R. "The Meaning of Mental Retardation." In R. Koch and J. Dobson (Eds.), The Mentally Retarded Living in the Community. Seattle, Wash.: Special Child Publishing Company, in press.

Meyerowitz, J. H. "Peer Groups and Special Classes." Mental Retardation, 1967, 5, 23-26.

Meyerowitz, J. H. "Self Derogations in Young Retardates and Special Class Placement." Child Development, 1962, 33, 443451.

Pasamanick, B., and Knobloch, H. "Early Language Behavior in Negro Children and the Testing of Intelligence." Journal of Abnormal and Social Psychology, 1955, 50, 401-402.

Porter, R. B. and Milazzo, T. C. "A Comparison of Mentally Retarded Adults Who Attended a Special Class With Those Who Attended Regular School Classes." Exceptional Children, 1958, 24, 410-412.

Riessman, F. The Culturally Deprived Child, New York: Harper, 1962.

Rosenthal, R. "Experimenter Expectancy and the Reassuring Nature of the Null Hypothesis Decision Procedure." Psychological Bulletin Monograph, 1968, 70, 30-47.

Rosenthal, R. and Jacobsen, L. Pygmalion in the Classroom. New York: Holt, Rinehart and Winston, 1968.

Terrell, G. Jr., Durkin, K., and Wiesley, M. "Social Class and the Nature of the Incentive in Discrimination Learning." Journal of Abnormal and Social Psychology, 1959, 59, 270 272.

Thorndike, R. L. Review of Rosenthal, R. and Jacobsen, L. "Pygmalion in the Classroom." American Educational Research Journal, 1968, 5, 708-711.

Thurstone, T. G. "An Evaluation of Educating Mentally Handicapped Children in Special Classes and in Regular Grades." U.S. Office of Education Cooperative Research Program, Project No. OE-SAE-6452. Chapel Hill: University of North Carolina, 1960.

Zigler, E. "Research on Personality Structure in the Retardate." In N. R. Ellis (Ed.), International Review of Research in Mental Retardation, Vol. 1. New York: Academic Press, 1966.

Zigler, E., and Butterfield, E. "Motivational Aspects of Changes in IQ Test Performance of Culturally Deprived Nursery School Children." Child Development, 1968, 39, 1-14. 
ISSUES

E TRENDS

EVALUATION: A NEW APPROACH

\section{James E. Whorton and Cary L. Reichard ${ }^{1}$}

In less than a decade the Special Education Instructional Material Center Network has come to play a major role in special education. The task of evaluation, a major charge of the Network, has not yet been clearly defined. Evaluation may be for the purpose of rating, adaptation, modification, improvement, or development. Instructional material evaluations have most often resulted in a rating: effective, ineffective, or placed somewhere along the continuum.

The most common form of evaluation involves either "field-testing" or "teacher ratings." Both of these methods produce essentially the same kind of results-a rating of a single material. The effectiveness of either method is clouded by the fact that each of the thousands of commercially produced materials available would require individual evaluation, a time-consuming and costly process.

We have long been concerned with the characteristics of mentally retarded children, but what are the characteristics of effective instructional materials? What makes one material better than another? The answers to these questions involve too much speculation. We may find a material to be effective, but why is it effective? Researchers have neglected this question in the past, but it is now receiving a good deal of attention.

Reichard and Reid (1970) conducted a study to determine whether or not spacing and line verification had any effect on a child's reading comprehension and speed of reading. The results indicated that those children reading the double-spaced material earned higher comprehension scores and read faster than those children having single-spaced material. In addition, those children reading double-spaced material with unverified margins did significantly better on the comprehension examination than those children reading double-spaced

1. James E. Whorton and Cary L. Reichard are Professors of Education, University of Florida. material with verified right margins.

Fowler, Hill, and Ward (1970) conducted a study involving characteristics of instructional materials. Classroom teachers of the educable mentally retarded were asked to rank on a six-point scale 104 characteristics of instructional materials. The scale ranged from highly important to highly unimportant. Less than 10 percent of the characteristics were rated unimportant. The remaining were rated important or highly important.

Whorton (1970) is conducting a research project to determine the dimensional effects of instructional materials. The project is designed to determine whether or not three-dimensional instructional materials facilitate learning more effectively than two-dimensional instructional materials.

The importance of the three previously-mentioned research projects focuses upon the approach taken toward the evaluation of instructional materials. In each, instructional materials were treated as a group rather than individually. The results of this kind of research will have several significant meanings. First is the contribution of knowledge useful toward the development of new materials. Research findings will provide principles which should be applied in the design and production of new materials.

Another important use of this type of research finding will be made by classroom teachers and SEIMC's. The results will be valuable in evaluating materials already on the market.

The results of this kind of research hopefully will begin a list of concrete principles; principles that will be useful in the development of new materials and principles that will be useful in the evaluation of current materials. Eventually we will be able to evaluate materials before they are ever produced. It would be unnecessary to look at commercially produced materials that had not been designed on the bases of these principles.

Although this type of research will not completely eliminate material evaluation, the task will be somewhat changed. Perhaps when enough principles are obtained and applied, materials will then be evaluated by teachers using only their specific and immediate teaching objective as the criterion.

\section{REFERENCES}

Fowler, R. E., Hill, S. A., and Ward, A. D. "Characteristics of 
Instructional Materials: A Survey." An unpublished project conducted at the University of Florida, 1970.

Reichard, C. L., and Reid, W. R. "An Investigation of Format for Reading Material for the Educable Mentally Retarded." The Journal of Reading, Vol. 13, No. 5, 1970.

Whorton, J. E. "The Dimensional Effects of Instructional Materials on Classroom Performance of the Educable Mentally Retarded." Research project under progress, University of Florida, 1970.

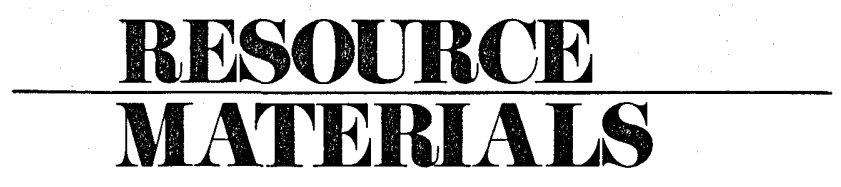

By Avaril Wedemeyer and Joyce Cejka

\section{STANWIX HOUSE}

The Functional Basic Reading Series is designed for children whose reading ages are significantly below their chronological ages. It differs from conventional readers in two respects: (1) in the rate, complexity, and repetition with which vocabulary and reading skills are presented, and (2) in the reconciling of chronological, mental, and social ages through illustrations and degrees of reading difficulty as presented in three complete programs of instruction. Skills are developed at four separate levels. Stanwix House, 3020 Chartiers Ave., Pittsburgh, Pa. 15204.

\section{HUDSON PHOTOGRAPHIC INDUSTRIES}

A new series of four filmstrips in the area of beginning mathematics for preschool through third grade youngsters is now available. The strips are in full-color and produced in consultation with primary grade teachers. Each strip covers a different area of math, using animal and nature themes, e.g., the feeding habits of a hamster; the growth of gerbil babies; the use of birds, caterpillars, and flowers to develop the beginning concepts of linear measurement; and a unique treatment of fractions. Each filmstrip is accompanied by a teacher's guide. The complete set of four titles is $\$ 28.50$ ( $\$ 7.50$ each) and available from Hudson Photographic Industries, Education Products Division, 2 South Buckhout St., Irvington-on-Hudson, N.Y. 10533.

\section{RICHTEXT PRESS}

A new approach to inspiring an interest in reading and numbers is featured in this new multi-sensory readiness program, designed for use in preschool through first grade. This first-step program helps the child grasp the concept that each letter has a sound, each group of letters form a word, and each group of words is an idea. Included in the complete program are books, a record album, a teacher's guide, and activity books. The complete program is $\$ 69.95$; each part is available separately. Richtext Press, 1224 W. Van Buren St., Chicago, Ill. 60607.

\section{EDUCATIONAL ACTIVITIES}

Learning Squares include 108 game cards containing instructional progression of learning games in self-control, serial memory, pattern, number and letter recognition, counting, mathematics, letter sounds, spelling, and reading. The 10 " $\times 10$ " square are soft, tough, rubber foam, ideal for all youngsters with learning handicaps as well as for all primary children. Available for $\$ 59.00$ from Educational Activities, Freeport, N.Y. 11520.

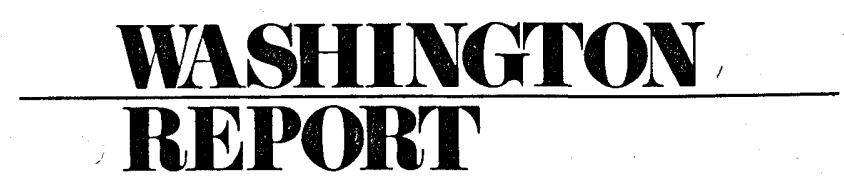

Three programs administered by the Aid to States Branch of the Bureau of Education for the Handicapped provide funds for educational aid to handicapped children.

Services authorized under the following legislation are available to handicapped children under 21 years of age attending public and private schools (preschool through grade 12).

1. The Public Law 89-313 Amendment to Title I of the Elementary and Secondary Education Act provides aid to states to encourage the development of new projects or supplementary projects which enrich or expand existing comprehensive educational programs. Funds will 
be provided for construction, remodeling, equipment, and inservice staff training if project applicants can show that these activities facilitate direct educational services to handicapped children.

Allocation of funds are made to state agencies which may conduct projects or contract with local school and educational agencies who submit project applications.

2. Part $B$ of the Education of the Handicapped Act (Public Law 91-230) provides aid to states for the "initiation, expansion and improvement of special education and related services to handicapped children." Eligible projects include a range of educational services from activities for preschoolers to academic and work-study programs for secondary school students. Also eligible are projects for diagnostic services, preparation of personnel, curricula and instructional materials and equipment if these activities can be shown to aid in providing direct service to handicapped children.

Allocations are made to state agencies which may develop projects or accept project applications from local schools and educational agencies.

3. Title III, Elementary and Secondary Education Act encourages school districts to "develop imaginative solutions to educational problems; to utilize research findings; and to create, design, and make intelligent use of educational centers and services."

The primary goal of the program is to incorporate new, high-quality projects and services into the special education program.

Services which may be offered are: diagnosis, counseling and remediation, inservice training, curriculum development, materials preparation, demonstration activities and community participation.

Of the Title II appropriation $85 \%$ will be administered by the states with the remaining $15 \%$ being controlled by the U.S. Commissioner of Education. Local education agencies should apply to state education agencies for project funds controlled by the state and to the U.S. Office of Education for funds administered by the Commissioner.

For additional information about any of these programs, contact: Chief, Aid to State Branch, Division of Educational Services, Bureau of Education for the Handicapped, U.S. Office of Education, 400 Maryland Avenue, S.W., Washington, D. C. 20202.

\section{ALEIT T}

The Conference on Visual Literacy will be held March 7-10, 1971 in Asilomar, California. Stressing visual literacy, the conference will form task forces from among its participants to demonstrate promising practices in training, learning, diagnosis, and remediation. There will be a multi-disciplinary forum for the many specialists who are interested in every aspect of visual literacy. Persons interested in participating may contact Dr. Francis Moakley, Director, AV Center, 1600 Holloway Avenue, San Francisco, California 94132.

The 49th Annual International Convention of the Council For Exceptional Children will be held April 1824, 1971 at The Fountainebleau Hotel, Miami Beach, Florida.

The Association for Children with Learning Disabilities will hold its 8th Annual International Conference at the Conrad Hilton Hotel in Chicago on March 17-20, 1971.

The Association for Supervision and Curriculum Development will hold its 26th Annual Conference at Kiel Auditorium in St. Louis March 6-9, 1971.

The National Association of School Psychologists will meet jointly with the California Association of School Psychologists at the San Francisco Hilton Hotel March 23-27, 1971.

The American Association on Mental Deficiency will have its annual meeting at The Shamrock Hilton in Houston June 13-19, 1971.

The European Association for Special Education will hold an International Trade Fair and Exhibition in Norrkoping, Sweden, July 25-August 2, 1971.

FOCUS ON EXCEPTIONAL CHILDREN back issues are available. Single copies $80 \phi, 2-9$ copies $70 \phi$, and 10 or more copies $50 \phi$ each. 


\section{CLASSROOM FOPUM}

Edited by Austin J. Connolly, University of Missouri

\section{PROBLEM 6}

Your supervisor has indicated that a continuing classroom interest center can make a contribution to your instructional program. Good interest centers are an extremely valuable teaching aide that few teachers adequately employ. Written guidelines on such interest centers are virtually non-existant. Thus, unanswered questions that you might have include: What are classroom interest centers? What is their value? How do they relate to the rest of the instructional program? What about classroom space? How do I implement them?

An interest center is essentially an area in the classroom reserved for one or more students to engage in activities that are motivating to them and contribute to the total curriculum. The activities that are found in an interest center should be purposeful and organized around a central theme. A classroom might have only one continuing interest center or it may possess as many as the teacher can effectively maintain. A common concern of teachers is the classroom space that such a center or centers would remove from use in their regular instruction. This objection suggests a very limited perspective of what constitutes instruction and the curriculum.

Interest centers provide students the opportunity of independent and group activity in a variety of topics and materials. Much of this activity should be in the form of inquiry experiences. Thus, interest centers have the flexibility to not only support more traditional classroom content, but also provide an effective means of broadening student experiences. In establishing an interest center the teacher must remember that these are voluntary experiences and not make them compulsory. However, she must consider them as a valuable part of her instructional program and plan, implement, and evaluate them accordingly.

In our brief discussion it is not possible to adequately present the step by step procedures a teacher follows when implementing an interest center. However, if the center is successful she will have assessed student needs, their needs, available space, and classroom and external resources. At this point she will probably have approached her students in a "brainstorming" session to identify those activities and themes they would like incorporated into the center. When interacting with her students the teacher must not "over-sell" the interest center. The center should not be regarded as a place for fun and games, rather, as a place for activity and inquiry in areas of interest to them.

The interest center should provide a variety of activities organized around a central theme. Below are three central themes with activities that are illustrative of what might be found in the center at different class levels.

Theme Activities by level

Nature Primary-pressing leaves Inter- class pet tracing leaves build bird house animal pictures scrapbook play zoo paper mache'

Secondary - Taxidermy ecology purification of water humane society project

Other themes might include: communication, community helpers, repair, money, current events, music, art, sex education, alcohol and drugs, If an interest center is to work, it must have variety. Evaluate its contents often.

The contribution of Mrs. Judith Gwillim, teacher, Columbia, Missouri earns her our thanks and a year's subscription to Focus on Exceptional Children.

\section{PROBLEM 8}

I teach a special class of primary level EMR children. My class is the only special class located in our elementary school. Yesterday, my children came in from recess very upset. They said children from other classes were calling them names and saying they were in the "dummy class." How should I have responded in this situation?

All readers are invited to send their solution and tell how they would handle Problem 8. The April 1971 issue will summarize contributions by readers. Focus on Exceptional Children will award complimentary subscriptions each month for the best solution. Send your response to the Editorial Offices, Focus on Exceptional Children, 6635 East Villanova Place, Denver, Colorado 80222. 


\section{INDEX - VOLUME 2}

Author Index

Altman, Reuben (March through May)

Artuso, Alfred A. (March 1970)

Blackhurst, A. Edward (December 1970)

Cawley, John F. (September 1970)

Cejka, Joyce (November through February)

Connolly, Austin J. (September through February)

Deno, Evelyn (January 1971)

Egkvist, Halvor (April 1970)

Erickson, Donald K. (December 1970)

Feltner, Raymond L. (April 1970)

Ferrara, Robert P. (May 1970)

Gallagher, Patricia A. (October 1970)

Hayman, Donald J. (May 1970)

Hewett, Frank M. (March 1970)

Higgins, Conwell (September 1970)

Iyengar, Kanthi S. (May 1970)

Kroth, Roger L. (May 1970)

Lane, Pauline M. (January 1971)

Liebe-Lindgreen, J. (April 1970)

Lovitt, Tom (November 1970)

MacMillan, Donald L. (February 1971)

Reichard, Cary L. (February 1971)

Sayre, Elizabeth (November 1970)

Schaff, Mary (November 1970)

Sletved, Henning (April 1970)

Smith, Linda (March through May)

Stables, Jean Marie (May 1970)

Stillwell, Robert J. (March 1970)

Taylor, Frank D. (March 1970)

Thomas, Elizabeth C. (April 1970)

Wedemeyer, Avaril (November through February)

Whelan, Richard J. (May 1970)

Whorton, James E. (February 1971)
Subject Index of Articles

An educational solution: engineered classroom (March 1970)

Perspectives on educating the mentally handicapped in Denmark (April 1970)

A team approach to mental health in a rural community school (April 1970)

Teacher application of behavior principles in home and classroom environments (May 1970)

Living centers: an alternative to special classes (May 1970)

Teaching arithmetic to mentally handicapped children (September 1970)

Mathematics for the handicapped: programming concepts (September 1970)

A synthesis of classroom scheduling techniques for emotionally disturbed children (October 1970)

The use of direct and continuous measurement to evaluate reading materials and pupil performance (November 1970)

Information resources for special educators (December 1970)

Some reflections on the use and interpretation of tests for teachers (January 1971)

Individual academic evaluation (January 1971)

Special education for the mildly retarded: servant or savant (February 1971)

Evaluation: a new approach (February 1971)

Classroom forum (monthly)

Issues and trends (monthly)

Resource materials (monthly)

Washington report (monthly

Publisher's Note: Volume 2, Number 3 (May 1970) was mistakenly identified as Volume I. 